\title{
I was always on my mind: The self and temporary forgetting
}

\author{
C. NEIL MACRAE \\ Dartmouth College, Hanover, New Hampshire
}

and

TAMSIN A. ROSEVEARE

University of Bristol, Bristol, England

\begin{abstract}
Previous research has demonstrated that the act of remembering can prompt the temporary suppression of related items in memory-that is, retrieval-inducedforgetting (Anderson, Bjork, \& Bjork, 1994). In extending work of this kind, the present research sought to identify some important boundary conditions of this effect. As expected, temporary forgetting was eliminated under task conditions that elicited distinctive encoding operations-specifically, when material was relevant to the self. This result is noteworthy since it identifies spontaneous processing operations that protect information from temporary forgetting, a finding that has important implications both for the emergence of this inhibitory effect in everyday life and for theoretical treatments of memory function.
\end{abstract}

Strange though it may seem, it is only by forgetting that people can remember the past in an orderly and productive manner (Anderson, R. A. Bjork, \& E. L. Bjork, 1994; Anderson \& Spellman, 1995; E. L. Bjork, R. A. Bjork, \& Anderson, 1998). Take, for instance, the commonplace task of locating one's car in a parking lot. Since memory is replete with competing alternatives (e.g., previous parking spots), this task can only be accomplished if one has the ability to inhibit the retrieval of rival recollections, otherwise it may take a bit of time to find one's car. To produce the desired (i.e., goal-relevant) response, one must be able to suppress the retrieval of potentially disruptive (i.e., competing) memories. Inspection of the available literature confirms that such instances of adaptive forgetting can be triggered in a seemingly paradoxical way. As Anderson and McCulloch (1999) have observed, "a growing body of research has shown that the very act of remembering a past event can cause forgetting of related material" (p. 608). In other words, item retrieval can prompt the temporary suppression of competing memories-a phenomenon that has been termed retrievalinduced forgetting (Anderson et al., 1994).

The paradigm that has been developed to investigate retrieval-induced forgetting in the laboratory has four distinct phases: a study phase, a retrieval-practice phase, a distractor phase, and a final test phase (see Anderson et al., 1994). In the study phase, participants are presented with a list of category-exemplarstimulus pairs and are instructed

The authors thank Reed Hunt and an anonymous reviewer for their comments on this work. Correspondence concerning this article should be addressed to N. Macrae, Department of Psychological and Brain Sciences, Dartmouth College, Moore Hall, Hanover, NH 03755 (e-mail: c.n.macrae@dartmouth.edu). to memorize the items (e.g., fruit-orange, drink-gin). Next, they perform directed retrieval practice on half of the studied exemplars from half of the categories by completing a series of cued-stem tests (e.g., fruit-or

During this retrieval-practice phase, participants are cued to recall each of the critical items on three occasions. Following the completion of a distractor task, participants are then given a recall test in which they are cued with each category name (e.g., fruit, drink) and are asked to recall any of the exemplars that were presented during the original study phase. Recall performance is assessed on three types of item: practiced items from practiced categories (e.g., orange, $\mathrm{Rp}+$ items), unpracticed items from practiced categories (e.g., melon, Rp- items), and unpracticed items from unpracticed categories (e.g., gin, Nrp items). The logic underlying this procedure is as follows: If retrieving an item inhibits the memorability of related information, participants should have greater difficulty recalling unpracticed items $(\mathrm{Rp}-)$ from the same category as the practiced items $(\mathrm{Rp}+)$ than they should recalling unpracticed items (Nrp) from a previously unpracticed category (i.e., $\mathrm{Rp}+>\mathrm{Nrp}>\mathrm{Rp}-$ ). As an emerging literature has demonstrated, this is precisely what happens. Prior retrieval of an item prompts the suppression of related material in memory (see Anderson \& Neely, 1996; E. L. Bjork et al., 1998).

Despite its obvious cognitive utility, the existence of temporary forgetting raises a number of important questions (R. A. Bjork, 1989). Notable among these is the issue of the boundary conditions of this effect. Put simply, does retrieval practice (i.e., remembering) inevitably give rise to the suppression of related material in memory, or is temporary forgetting moderated by a variety of factors (see also Anderson \& McCulloch, 1999; Ciranni \& Shima- 
mura, 1999; MacLeod \& Macrae, 2001; Macrae \& MacLeod, 1999; Smith \& Hunt, 2000)? This turns out to be a critical issue when one considers memory function in many everyday task contexts (Macrae \& MacLeod, 1999: Shaw, Bjork, \& Handal, 1995). Although it is evidently adaptive to minimize the disruptive influence of competing recollections, on many occasions this might be precisely the material that people are striving to recall following an initial period of guided retrieval (Radvansky \& Zacks, 1991). Thus, if this information is forgotten, even temporarily, goal attainment might be blocked and people would be unable to realize their behavioral intentions. This problem would be particularly pronounced in settings in which people are required to extract material from complex knowledge representations, such as information about the self (Kihlstrom \& Cantor, 1984). Whether the inquisitor is a colleague, prospective employer, or traffic cop, it would be decidedly counterproductiveif a prior period of guided retrieval prompted one to forget information about one's contact details, employment history, or license plate. That memory lapses such as these occur with relative infrequency, however, would tend to suggest that self-relevant material might be resistant to temporary forgetting, a possibility we explore in the present investigation.

Recent research has revealed that a critical determinant of the emergence of temporary forgetting is the nature of the encoding operations that are undertaken on to-beremembered information. For example, when participants are instructed to integrate the material on the study list or to think about the relative distinctiveness of the various items, temporary forgetting is attenuated or even eliminated (Anderson \& McCulloch, 1999; Smith \& Hunt, 2000). That these strategies impede the emergence of temporary forgetting has important implications when one considers the self and memory function, as many researchers have argued that self-relevant material spontaneously attracts the attention of distinctive encoding operations (see Bower \& Gilligan, 1979; Kihlstrom \& Cantor, 1984; Klein \& Kihlstrom, 1986; Klein \& Loftus, 1988). Thus, the experimentally guided encoding strategies that have been shown to eliminate temporary forgetting in the laboratory (Anderson \& McCulloch, 1999; Smith \& Hunt, 2000) might be just the operations that are implemented spontaneously by perceivers when they process self-relevant material (Klein \& Loftus, 1988). If so, of course, one would expect self-relevant information to be resistant to temporary forgetting. We investigated this possibility in the following experiment.

\section{METHOD}

\section{Participants and Design}

Sixty undergraduate students (21 men and 39 women) participated in the experiment. The experiment had a 3 (target: self or best friend or other) $\times 3$ (item type: $\mathrm{Rp}+, \mathrm{Rp}-$, or $\mathrm{Nrp}$ ) mixed design with repeated measures on the second factor.

\section{Procedure and Stimulus Materials}

The participants arrived at the laboratory individually, were greeted by a female experimenter, and were randomly assigned to one of the treatment conditions. The procedure comprised four phases: a study phase, a retrieval-practice phase, a distractor phase, and a final test phase (see Anderson et al., 1994). The participants were informed that their task was to memorize a number of gifts. They were then given one of three instructions: (1) to imagine that they themselves had purchased the gifts, (2) to imagine that the gifts had been purchased by their best friend, or (3) to imagine that the gifts had been purchased by an unspecified other. This manipulation was expected to elicit self-referential processing in the critical experimental condition (i.e., gifts purchased by self), but not in the other two conditions. In the study phase, the participants were presented with index cards detailing the gifts: 10 gifts were indoor items (poster, lamp, scales, vase, chair, computer, desk, trunk, kettle, cushion), and 10 gifts were outdoor items (statue, rake, bicycle, shed, bench, hammock, tent, gnome, parasol, fountain). The order of presentation of the lists was counterbalanced, and the presentation of the gifts was randomized for each participant. Each set of gifts was divided into two subgroups (each containing five items) for the purpose of creating a practiced (i.e., $\mathrm{Rp}+$ ) and an unpracticed (i.e., $\mathrm{Rp}-$ ) set of items (see Anderson et al., 1994). Each card was presented for $5 \mathrm{sec}$, the participants were instructed to turn over the card when an electronic metronome in the laboratory emitted an audible bleep.

Immediately after the study phase, the participants were presented with cards that probed their memory for half of the gifts from one of the stimulus sets. Each card contained a cue, plus a hint about the identity of the gift in question (e.g., outdoor-pa___ ). The participants were required to recall and write down the gift in response to each cue. Each cue card was presented to the participants on three occasions, giving a total of 15 practice-retrieval trials. The presentation of the cue cards was randomized for each participant, and counterbalancing ensured that each of the items appeared equally often in the $\mathrm{Rp}+, \mathrm{Rp}-$, and $\mathrm{Nrp}$ conditions. After the retrieval-practice phase, the participants were given a 5-min distractor task in which they were required to write down as many countries of the world as possible. This was followed by a cuedrecall task in which the participants were requested to reproduce (i.e., write down) the gifts. The participants were given $5 \mathrm{~min}$ to complete this task. Finally, the participants were requested to rate the extent to which they had imagined potential recipients for the gifts during the study phase. This question was included in order to assess any spontaneous distinctive processing that took place during the task (e.g., "I'd give the gnome to Angela"). On the basis of previous research (Klein \& Loftus, 1988), we expected the participants in the self condition to report more imaginary musings (i.e., recipients for the gifts) than would their colleagues in either of the other two conditions. Ratings were furnished on a 9-point scale (1 $=$ did not imagine recipients for the gifts; $9=$ imagined recipients for the gifts). On completion of this task, the participants were debriefed, thanked for their assistance, and dismissed.

\section{RESULTS AND DISCUSSION}

The retrieval-practice success rates in this experiment were as follows: self (88\%), best friend (91\%), and other $(86 \%)$. To determine whether retrieval practice enhanced the memorability of Rp+ items, a 3 (target: self or best friend or other) $\times 2$ (item type: $\mathrm{Rp}+$ or Nrp) mixedmodel analysis of variance (ANOVA) was performed on the data (see Table 1). This revealed a main effect only of item type on recall performance, so that the participants remembered more $\mathrm{Rp}+$ than $\operatorname{Nrp}$ items $[F(1,57)=57.51$, $p<.0001]$. This effect confirms the recollective benefits of retrieval practice. To determine whether a prior period of retrieval practice impaired the memorability of related (i.e., $\mathrm{Rp}-$ ) items, a 3 (target: self or best friend or other) 
Table 1

Recall Performance as a Function of Target and Item Type

\begin{tabular}{lcccccc}
\hline & \multicolumn{3}{c}{ Item Type } & & \multicolumn{2}{c}{ Difference Score } \\
\cline { 2 - 4 } \cline { 6 - 7 } Target & $\mathrm{Rp}+$ & $\mathrm{Rp}-$ & $\mathrm{Nrp}$ & & $(\mathrm{Rp}+)-\mathrm{Nrp}$ & $(\mathrm{Rp}-)-\mathrm{Nrp}$ \\
\hline Self & .81 & .57 & .55 & & .26 & .02 \\
Best friend & .83 & .35 & .60 & & .23 & -.25 \\
Other & .76 & .26 & .48 & & .28 & -.22 \\
\hline
\end{tabular}

$\times 2$ (item type: Rp - or Nrp) mixed-model ANOVA was performed on the data (see Table 1). This revealed main effects of target $[F(2,57)=7.29, p<.002]$ and item type $[F(1,57)=18.79, p<.0001]$ on recall performance. As expected, however, these effects were qualified by a target $\times$ item type interaction $[F(2,57)=6.44, p<.003]$. Simple effects analysis confirmed that the participants in both the best friend $[F(1,57)=17.08, p<.001]$ and other condition $[F(1,57)=14.41, p<.001]$ remembered more Nrp than $\mathrm{Rp}-$ items, thereby demonstrating the conventional retrieval-induced forgetting effect. A comparable forgetting effect did not emerge in the self condition $[F(1,57)<$ 1, n.s.]. Thus, as expected, self-referential processing eliminated the emergence of temporary forgetting. ${ }^{1}$

We anticipated that the participants in the self condition would be most likely to imagine possible recipients for the gifts. A single factor (target: self or best friend or other) between-subjects ANOVA on participants' ratings confirmed this prediction $[F(2,57)=10.41, p<.0001]$. Post-hoc Tukey tests revealed that the participants in the self condition $(M=7.40)$ were more likely to imagine recipients for the gifts than were their colleagues in either the best friend $(M=4.60)$ or other condition $(M=3.75$, both $p \mathrm{~s}<.01$ ). As expected, therefore, under conditions that enhanced the distinctiveness of the items on the study list, temporary forgetting was eliminated (Smith \& Hunt, 2000).

It is worth noting, however, that an alternative explanation may be offered for the present effects. Perhaps temporary forgetting emerged in the best friend and other conditions not as a result of retrieval-induced forgetting (i.e., item suppression), but because of the operation of output interference during the final recall task (see Anderson \& Spellman, 1995). It is possible that the participants given a prior period of retrieval practice might initially retrieve the highly accessible Rp + items from memory. If so, this may interfere with the retrieval of the less accessible $\mathrm{Rp}-$ items, thereby diminishing performance on these items. Of course, such a process would have some rather predictable effects. Specifically, the pattern of results that is indicative of retrieval-induced forgetting should emerge only for those participants who initially retrieve $\mathrm{Rp}+$ items. To establish whether this was indeed the case, we classified the participants in the best friend and other conditions according to the extent to which they commenced their recall sequences with $\mathrm{Rp}+$ or $\mathrm{Rp}-$ items (see Macrae \& MacLeod, 1999). First, for each participant, we calculated a difference score by subtracting the average recall position of $\mathrm{Rp}+$ items from the average recall posi- tion of Rp - items. The participants were then sorted by means of a median split to produce an early-Rp+ group and an early-Rp- group. The inhibition effects for these two groups were then calculated in the conventional way [i.e., $(\mathrm{Rp}-)-\mathrm{Nrp}$ ]. Importantly, for neither the best friend nor the other condition did the early-Rp+ group produce a larger inhibitory effect than the early-Rpgroup: best friend [respective $M$ s: -.23 vs. $-.27 ; t(18)<$ 1 , n.s.], other [respective $M$ s: -.19 vs. $-.25 ; t(18)<1$, n.s.]. Thus, these findings imply that the temporary forgetting effects observed in the present experiment were not a consequence of output interference during the final recall test.

\section{GENERAL DISCUSSION}

The ability to suppress the retrieval of competing or disruptive memories is clearly a valuable cognitive skill. Indeed, without such a capacity, even straightforward tasks would be fraught with difficulty. Locating one's car in a parking lot, furnishing one's telephone number to a friend, or providing a restaurant recommendation to a relative are tasks made simple through temporary forgetting. Yet, if this process operated in an unconstrained manner, difficulties would surely emerge. After all, in many task contexts, people may strive to retrieve a consecutive list of facts about a given topic. As Anderson and McCulloch (1999) have argued, "our ability to reason about objects and events depends critically on our capacity to form and retain mental representations with many interrelated parts. If we are to avoid decomposing such representations, retrieval of any one part should proceed without suppressing the others" (p. 608). The self is an excellent case in point. Social cognition would be a perilous affair if guided retrieval prompted one to lose access, even momentarily, to self-related knowledge. Under these conditions, not only would one be unable to retrieve personal information, but the stability of one's self-concept may also be compromised. As demonstrated in the present research, however, these outcomes are unlikely to emerge. Instead, the distinctive encoding operations that are undertaken on self-relevant material appear to protect this information from the possible perils of temporary forgetting.

Notwithstanding the potential importance of the present findings, a couple of caveats are worth mentioning. First, were the observed forgetting effects the result of the active suppression of related items in memory? To provide unequivocal evidence for the operation of inhibitory mechanisms in memory, researchers have recently used what is termed the independent-cue technique (see Anderson \& Spellman, 1995). The gist of this technique is that researchers probe item memory (e.g., banana) on the final recall task with a cue that differs from the one used at encoding (e.g., fruit vs. monkey). If the item is truly suppressed, temporary forgetting should emerge even when a different retrieval cue is presented to participants during the final recall test (Anderson \& Neely, 1996). Although the independent-cue technique 
was not used in the present experiment, the findings are nevertheless suggestive of the operation of inhibitory mechanisms in memory. Additional analyses revealed a pattern of results that would not be expected if output interference was driving the observed effects (see also MacLeod \& Macrae, 2001; Macrae \& MacLeod, 1999). Notwithstanding this observation, however, a useful task for future research would be to replicate the present effects by using the independent-cue technique. Work of this kind will clarify the basis of the memory impairment observed in the present experiment.

The second caveat concerns the generality of the observed effects and their implications for current understanding of the self-memory system. Distinctive processing operations appear to inoculate self-relevant information (and indeed other classes of material) from temporary forgetting. Consider, the to-be-remembered items in the present experiment. When self-referential processing was triggered (i.e., the self condition), the participants imagined potential recipients for the gifts. In so doing, of course, they engaged in item-specific processing that enabled them to differentiate the gifts on the study list. In turn, this differentiation protected the items from temporary forgetting (Smith \& Hunt, 2000). Thus, the processing operations that moderate the emergence of temporary forgetting in the laboratory might be the same strategies that are implemented spontaneously by perceivers when information is encoded in the context of the self. But what of self-referential material that has resided in memory for a considerable period of time (i.e., weeks, months, years)? Like material that is momentarily selfrelevant (i.e., the gifts in the present experiment), would this information also be resistant to temporary forgetting? As a complex knowledge structure, the self is known to foster the elaborative integration of information in memory (Bower \& Gilligan, 1979; Kihlstrom \& Cantor, 1984; Klein \& Kihlstrom, 1986; Klein \& Loftus, 1988). As a result of this organizational complexity, it is probable that multiple retrieval routes exist for items of autobiographical knowledge, alternative retrieval routes that may serve to thwart the emergence of temporary forgetting (Anderson \& McCulloch, 1999; Anderson \& Neely, 1996; Radvansky \& Zacks, 1991). Thus, even established autobiographical knowledge may be resistant to temporary forgetting, although it remains for future research to demonstrate this effect. Remembering may indeed prompt temporary forgetting, but not, it would appear, when selfreferential processing is involved.

\section{REFERENCES}

Anderson, M. C., BJork, R. A., \& BJork, E. L. (1994). Remembering can cause forgetting: Retrieval dynamics in long-term memory. Journal of Experimental Psychology: Learning, Memory, \& Cognition, 20, 1063-1087.

Anderson, M. C., \& MCCulloch, K. C. (1999). Integration as a general boundary condition on retrieval-induced forgetting. Journal of Experimental Psychology: Learning, Memory, \& Cognition, 25, 608-629. Anderson, M. C., \& NeELY, J. H. (1996). Interference and inhibition in memory retrieval. In E. L. Bjork \& R. A. Bjork (Eds.), Memory: Hand- book of perception and cognition (pp. 237-313). New York: Academic Press.

Anderson, M. C., \& Spellman, B. A. (1995). On the status of inhibitory mechanisms in cognition: Memory retrieval as a model case. Psychological Review, 102, 68-100.

Bjork, E. L., Bjork, R. A., \& Anderson, M. C. (1998). Varieties of goal-directed forgetting. In J. M. Golding \& C. M. MacLeod (Eds.), Intentional forgetting (pp. 103-137). Mahwah, NJ: Erlbaum.

BJork, R. A. (1989). Retrieval inhibition as an adaptive mechanism in human memory. In H. L. Roediger \& F. I. M. Craik (Eds.), Varieties of memory and consciousness: Essays in honour of Endel Tulving (pp. 309-330). Hillsdale, NJ: Erlbaum.

Bower, G. H., \& Gilligan, S. G. (1979). Remembering information related to one's self. Journal of Research in Personality, 13, 420-432.

Ciranni, M. A., \& Shimamura, A. P. (1999). Retrieval-induced forgetting in episodic memory. Journal of Experimental Psychology: Learning, Memory, \& Cognition, 25, 1403-1414.

Kinlstrom, J. F., \& Cantor, N. (1984). Mental representations of the self. In L. Berkowitz (Ed.), Advances in experimental social psychology (Vol. 17, pp. 1-47). New York: Academic Press.

Klein, S. B., \& Kinlstrom, J. F. (1986). Elaboration, organization, and the self-reference effect in memory. Journal of Experimental Psychology: General, 115, 26-38.

KLEIN, S. B., \& Loftus, J. (1988). The nature of self-reference encoding: The contributions of elaborative and organizational processes. Journal of Personality \& Social Psychology, 55, 5-11.

MacLeod, M. D., \& Macrae, C. N. (2001). Gone but not forgotten: The transient nature of temporary forgetting. Psychological Science, 12, 148-152.

Macrae, C. N., \& MacLeod, M. D. (1999). On recollections lost: When practice makes imperfect. Journal of Personality \& Social Psychology, 77, 463-473.

RADVANSKY, G. A., \& ZACKs, R. T. (1991). Mental models and the fan effect. Journal of Experimental Psychology: Learning, Memory, \& Cognition, 17, 940-953.

Shaw, J. S., III, BJork, R. A., \& Handal, A. (1995). Retrieval-induced forgetting in an eyewitness-memory paradigm. Psychonomic Bulletin \& Review, 2, 249-253.

Smith, R. E., \& Hunt, R R. (2000). The influence of distinctive processing on retrieval-induced forgetting. Memory \& Cognition, 28, 503-508.

\section{NOTE}

1. Of course, it is not the self per se that eliminates temporary forgetting, rather it is the fact that distinctive encoding operations are undertaken when self-relevant material is encountered (Klein \& Kihlstrom, 1986; Klein \& Loftus, 1988). If these operations were implemented for other social targets, one would also expect temporary forgetting to be eliminated (Smith \& Hunt, 2000). To investigate this prediction, 40 additional participants were required to memorize the gifts used in the present experiment. All the participants were told that the gifts were purchased by their best friend, but half of the participants were also instructed to try to imagine possible recipients for the items. The results of a 2 (target: control or elaborate) $\times 3$ (item type: Rp + or Rp - or Nrp) mixed-model ANOVA confirmed our prediction. On the critical inhibitory effect $(\mathrm{Rp}-\mathrm{vs}$. Nrp), the analysis revealed a target $\times$ item type interaction $[F(1,38)=17.22, p<.0002]$. Simple effects analysis confirmed that the participants in the control condition remembered more Nrp than Rp - items $[F(1,38)=33.27, p<.0003]$, thereby demonstrating the standard retrieval-induced forgetting effect $(M \mathrm{~s}: .635 \mathrm{vs}$. .350). Importantly, a comparable forgetting effect did not emerge in the elaborate condition $[F(1,38)<1$, n.s.; $M$ s: .545 vs. .550]. Thus, even when the target is one's best friend, by enhancing the distinctiveness of the items on the study list, retrieval-induced forgetting can be eliminated (see Smith \& Hunt, 2000). Additional analysis confirmed that the forgetting effect observed in the control condition was not a consequence of output interference during the final recall test [respective $M \mathrm{~s}$ : early-Rp $+=-.26$, early-Rp $-=-.30 ; t(18)<1$, n.s.].

(Manuscript received June 6, 2001; revision accepted for publication October 1, 2001.) 